\title{
COST-EFFECTIVENESS OF CADAVERIC AND LIVING-DONOR LIVER TRANSPLANTATION
}

\author{
Markus Sagmeister, ${ }^{1,3}$ Beat Mullhaupt,${ }^{1}$ Zakiyah Kadry, ${ }^{2}$ Gerd A. Kullak-Ublick, ${ }^{1}$ \\ Pierre A. Clavien, ${ }^{2}$ AND Eberhard L. RenNeR ${ }^{1}$
}

Division of Gastroenterology and Hepatology, and Department of Visceral and Transplantation Surgery, University Hospital, 8091 Zürich, Switzerland

Background. Cadaveric liver transplantation (5year survival $>80 \%$ ) represents the standard of care for end-stage liver disease (ESLD). Because the demand for cadaveric organs exceeds their availability, living-donor liver transplantation has gained increasing acceptance. Our aim was to assess the marginal cost-effectiveness of cadaveric and living-donor orthotopic liver transplantation (OLT) in adults with ESLD.

Methods. Using a Markov model, outcomes and costs of ESLD treated (1) conservatively, (2) with cadaveric OLT alone, and (3) with cadaveric OLT or living-donor OLT were computed. The model was validated with published data. The case-based scenario consisted of data on all 15 ESLD patients currently on our waiting list (3 women, 12 men; median age, 48 years [range, 33-59 years]) and on the outcome of all OLT performed for ESLD at our institution since $1995(n=51$; actuarial 5-year survival 93\%). Living-donor OLT was allowed in $15 \%$ during the first year of listing; fulminant hepatic failure and hepatocellular carcinoma were excluded.

Results. Cadaveric OLT gained on average 6.2 quality-adjusted life-years (QALYs) per patient compared with conservative treatment, living-donor OLT, an additional 1.3 QALYs compared with cadaveric OLT alone. Marginal cost-effectiveness of a program with cadaveric OLT alone and a program with cadaveric and living-donor OLT combined were similar ( $€$ 22,451 and $€$ 23,530 per QALY gained). Results were sensitive to recipient age and postoperative survival rate.

Conclusions. Offering living-donor OLT in addition to cadaveric OLT improves survival at costs comparable to accepted therapies in medicine. Cadaveric OLT and living-donor OLT are cost-effective.

Cadaveric orthotopic liver transplantation (OLT) has become widely accepted as standard of care for end-stage liver disease (ESLD). Thus in the last 10 years the number of cadaveric OLTs tripled from 24 in 1989 to 75 in 1999 in Switzerland (population, 6.8 million inhabitants) (1). One current challenge is an increasing waiting list caused by the progressive shortage in donor organs. This problem of lengthening waiting lists is faced by all transplantation units (2). With longer waiting times the morbidity and mortality of patients waiting for OLT are increasing, and costs of patients requiring inpatient treatment are rising without improvement of survival. One approach to cope with the donor shortage is the use of living donors $(3,4)$.

\footnotetext{
${ }^{1}$ Division of Gastroenterology and Hepatology.

${ }^{2}$ Department of Visceral and Transplantation Surgery.

${ }^{3}$ Address correspondence to: M. Sagmeister, MD, Division of Gastroenterology and Hepatology, University Hospital, Rämistrasse 100, 8091 Zürich, Switzerland. E-mail: markus.sagmeister@dim.usz.ch
}

The clinical impact of the introduction of living-donor OLT is complex as there is a trade-off of benefits for the recipient and the risks for the donor. The main benefits for the recipient are a decreased waiting time and lower perioperative complications because the operation is performed electively with a short reperfusion time (5). On the other side, the operative risks for the donor need to be considered (6).

The impact of a living-donor OLT program on the healthcare system is unknown. On the one hand, costs for patients on the waiting list are reduced with a shorter waiting time. On the other hand, transplantation costs rise with the higher number of transplantations performed. Additional costs arise with the donor hepatectomy and the associated donor surveillance program. Despite the recent reduction of hospitalization costs for transplantations with shorter lengths of stay, total costs including the follow-up treatment remain high (7-10).

To our knowledge there are no published studies on the cost-effectiveness of living-donor OLT for ESLD and there is no analysis of the impact of a living-donor OLT program on a transplantation center (4). Therefore, we aimed at performing an assessment of the cost-effectiveness of cadaveric OLT and living-donor OLT based on recent costs and effectiveness data and at analyzing the clinical and economic impact of a living-donor OLT program on a transplantation center.

\section{MATERIALS AND METHODS}

We created a Markov-based decision model to simulate clinical and economic effects of cadaveric OLT and living-donor OLT in ESLD (Fig. 1). Our analysis is based on the entire cohort of patients with ESLD on the waiting list for transplantation at the University Hospital Zürich and takes into consideration the outcomes of the natural history of ESLD, a cadaveric OLT program, and a program with cadaveric OLT and living-donor OLT combined. The model starts with an intention-to-treat decision and allows us to model cohorts of patients with ESLD and to compare the outcome of the natural history of ESLD and treatment options (cadaveric OLT and living-donor OLT). The cohorts move through predefined health states by given transition probabilities over time until all patients have entered the death state. Transition probabilities are derived from patients observed at the University Hospital Zürich and from the literature. The model is applied to the waiting list for liver transplantation at the University Hospital Zürich, and age-specific modeling of patients with ESLD is performed. Time is represented by annual cycles. The model allows a clinical as well as an economic evaluation of cadaveric OLT and living-donor OLT. Decision Maker (11) was used for our analyses.

\section{Cadaveric OLT}

To simulate the natural history of decompensated cirrhosis we applied an annual mortality rate of $24 \%$ based on long-term studies 


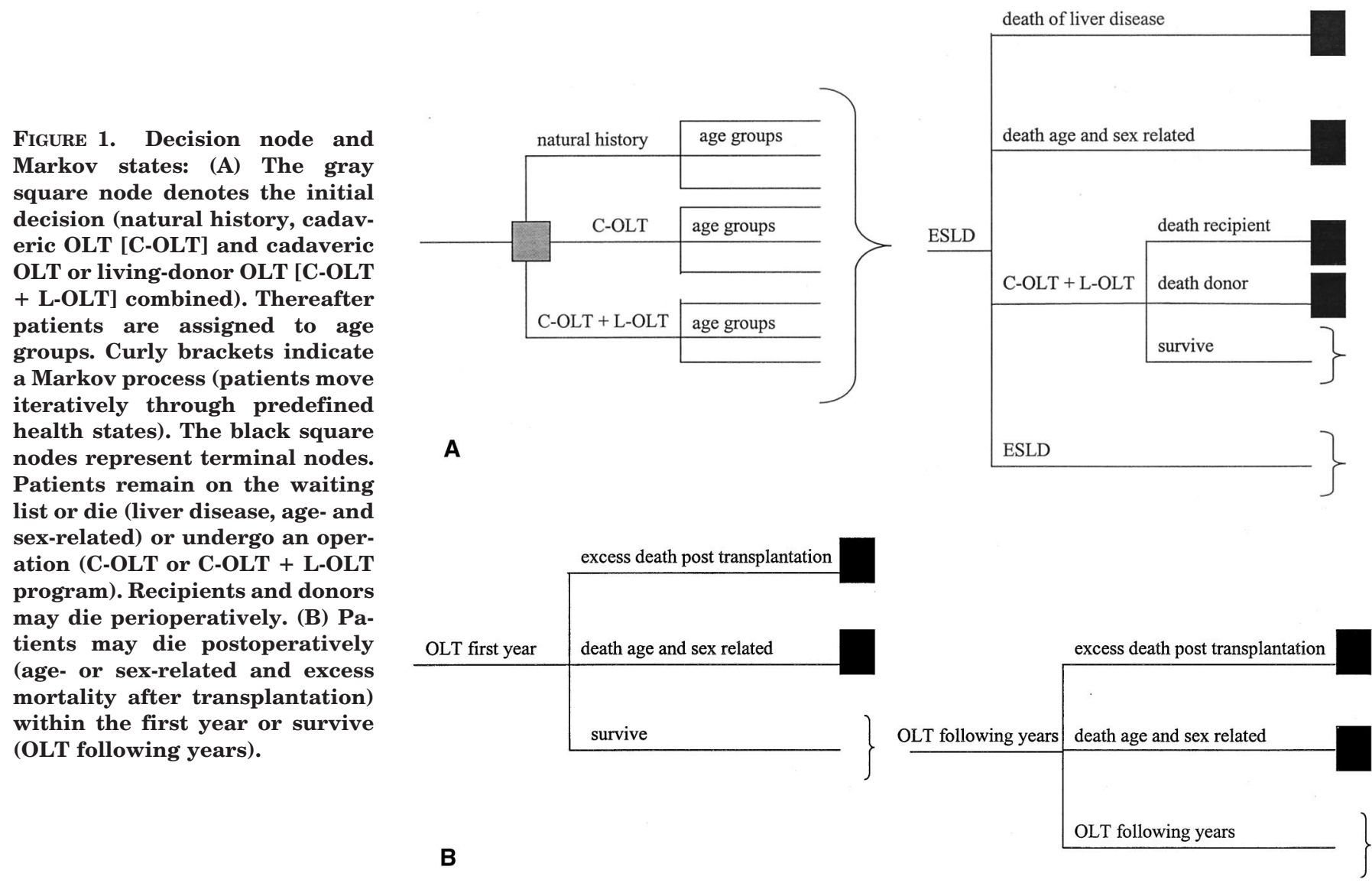

(12-15). The likelihood of OLT was derived from the waiting list at the University Hospital Zürich (current annual probability of OLT is $39 \%$; Table 1). A perioperative (3 months) recipient mortality of $1.9 \%$ was applied based on a consecutive series of 51 cadaveric OLTs for ESLD during the period January 1995 through October 2000 (University Hospital Zürich, unpublished data). According to the data from the European Liver Transplantation Registry (ELTR), the survival after OLT of patients with cirrhosis as the first indication of liver transplantation is similar for different etiologies (viral-related cirrhosis, alcoholic cirrhosis, primary biliary cirrhosis, autoimmune cirrhosis, secondary biliary cirrhosis, cirrhosis of other causes) (16), and therefore we calculated on the basis of a 5-year survival of $93 \%$ for ESLD, based on all cadaveric OLTs performed for ESLD at the University Hospital Zürich since 1995 ( $n=51$; median age, 48 years; range, 33-59 years). We assumed a constant annual cadaveric OLT probability for all patients over time until all patients died from ESLD or other causes. OLT is considered possible until the age of 69 years. Age-specific mortality data (all other causes) were obtained from official Swiss mortality data (17). To adjust mortality rates to probabilities we applied the declining exponential approximation of life expectancy (18).

\section{Living-Donor OLT}

We assumed that $30 \%$ of all recipients could identify a possible donor for formal evaluation and that $15 \%$ of all recipients would undergo living-donor OLT (19). We defined a perioperative donor mortality of $0.5 \%$ (19-21). A donor age of 30 years with a life expectancy of 46 years was assumed (22). Perioperative recipient mortality and long-term mortality was calculated for living-donor OLT in the same way as for cadaveric OLT (23). Living-donor OLT was considered possible only within the first year of listing. We did not include long-term complications for the donor as these have not been evaluated systematically (24).

TABLE 1. Baseline assumptions and ranges tested in the sensitivity analysis

\begin{tabular}{lccc}
\hline \multicolumn{1}{c}{ Variable } & Baseline probability & Range tested & Reference \\
\hline Recipient age & Median: 48 years & $20-80$ years & Waiting list 2000, USZ \\
Likelihood of C-OLT & $39 \%$ & $0-60 \%$ & Waiting list 1995-2000, USZ \\
Likelihood of L-OLT & $15 \%$ & $0-30 \%$ & $(19)$ \\
Perioperative mortality recipient & $1.95 \%$ & $1.95-10 \%$ & USZ, 1995-2000 (38) \\
Perioperative mortality donor & $0.5 \%$ & $0.5-10 \%$ & $(20,21,23)$ \\
5 -year survival OLT & $93 \%$ & $93-67 \%$ & USZ, 1995-2000 (38) \\
Donor age & 30 years & $20-50$ years & $(6)$ \\
5-year survival (natural history) & $30 \%$ & $10-40 \%$ & $(13-15)$ \\
Discount rate & $3 \%$ & $0-7 \%$ & $(28)$ \\
\hline
\end{tabular}

C-OLT, cadaveric OLT; L-OLT, living-donor OLT; USZ, University Hospital Zürich. 


\section{Cost Data}

We included total direct costs for the year 1999 from a societal perspective (Table 2). Lifetime costs were calculated. Cost evaluations followed actual treatment patterns in Switzerland. Average length of stay per complication was based on data from the Swiss Hospital Association (25). Costs of OLT were derived from an analysis of the Swiss Hospital Institute (26). We updated these data to account for a shorter length of stay (25). The frequency of complications was estimated by a panel of Swiss physicians and analyses of one university center (EL Renner, unpublished data). The costs for donor evaluation were derived from a protocol for evaluation of potential living-liver donors derived by Marcos et al.(5), which is identical to the one used at our hospital. Costs of donor liver lobectomy were based on official cost data (27). Future costs as well as future clinical benefits were discounted by $3 \%(28)$.

\section{Quality of Life}

We derived the utility of health states in the model by a time trade-off technique and calculated quality-adjusted life-years (QALYs) (29). We applied utility values of 0.7 for the first year after transplantation, and 0.8 for the years thereafter; for life-years with decompensated cirrhosis after listing for transplantation, we assigned a utility value of 0.6 (30). These utility estimates reflect the Karnofsky performance status of published quality-of-life studies (31-34).

\section{Model Validation}

We validated our model by comparing the survival estimates of the model with published survival rates. The model estimates for the natural history (2- and 7-year survival, 63.7 and $20.2 \%$, respectively) were very close to the published data (2- and 7-year survival, 62.5 and 20\%, respectively) (35). The model of the OLT program was validated against survival data after cadaveric OLT at the University Hospital Zürich. Again the model estimates (2- and 5-year survival, $96.4 \%$ and $92.4 \%$, respectively) were close to the observed data (2- and 5-year survival, 96\% and 93\%, respectively).

\section{RESULTS}

The cadaveric OLT program gives a patient an additional gain of 6.2 QALYs compared with the natural history and accrues additional costs to society of $€ 139,633$ (3\% discount rate). The marginal costs for one additional QALY gained per patient with ESLD treated by a cadaveric OLT amount to $€$ 22,451. Compared with cadaveric OLT alone, a program with cadaveric OLT and living-donor OLT combined offers a patient an additional 1.3 QALYs at additional costs of $€ 31,076$ (Table 3).

The natural history of ESLD without transplantation results in an average life expectancy per patient of 4.0 years, and $97.7 \%$ of all patients will die of their liver disease. With a combined cadaveric OLT and living-donor OLT program the average life expectancy increases to 12.7 years, and the majority of all patients $(52.4 \%)$ will die with a natural ageand sex-specific mortality. Therefore a combined cadaveric
OLT and living-donor OLT program will cause a shift from a liver disease-related mortality to a natural age- and sexspecific mortality (Table 4).

\section{Sensitivity Analysis}

We tested our results by modulating variables within a broad range. We considered a variable as critical if it pushes the marginal cost-effectiveness of the base case above $€$ 35,000 per QALY. We have chosen a conservative cost-effectiveness limit that is lower than the usually accepted US $\$ 50,000$ ( $€ 53,460$ ) per QALY gained (36) as health-care costs (costs per gross national product) are approximately $30 \%$ lower in Switzerland than in the United States (37).

\section{Variation of Recipient Survival}

Not unexpectedly the cost-effectiveness was sensitive to the recipient survival rates (Fig. 2). We tested a 5-year survival of $83 \%$ as documented by the ELTR (1988-1998, patients without a risk factor) (38), which leads to a costeffectiveness of $€ 26,000 / Q A L Y$. A 5-year survival after cadaveric OLT of $93 \%$ as observed at the University Hospital Zürich (1995-2000) might not be representative of patients or patterns of care at other centers. Additionally the patient cohort observed at the University Hospital Zürich is transplanted 7 years later than the ELTR data with improved techniques. On decreasing the 5-year recipient survival rate below 69\% the marginal cost-effectiveness exceeds $€ 35,000 /$ QALY (cadaveric OLT alone). If we consider a program with cadaveric OLT and living-donor OLT combined, the costeffectiveness exceeds $€ 35,000 / \mathrm{QALY}$ on decreasing the 5 -year survival rate below $72 \%$.

\section{Variation of Patient Age}

The median age of patients on the waiting list for ESLD at the University Hospital Zürich is 48 years (Fig. 3). With rising age, cost-effectiveness decreases as the natural (ageand sex-specific) life expectancy decreases. Until the age of 60 years, the cost-effectiveness stays stable below $€ 30,000 /$ QALY. For patients older than 65 years, the cost-effectiveness rises rapidly. Patients older than 75 years show a costeffectiveness beyond $€ 35,000 /$ QALY.

\section{Variation of Cadaveric OLT Probability (Compared With Conservative Treatment)}

When varying the probability of cadaveric OLT (waiting time), marginal costs will change simultaneously with marginal effectiveness and therefore the marginal cost-effectiveness will stay stable below € 35,000/QALY (Fig. 4). We tested our results by varying probabilities of cadaveric OLT (range, $0-60 \%)$. Nevertheless costs for the transplantation center

TABLE 2. Cost estimates and range tested in the sensitivity analysis

\begin{tabular}{|c|c|c|}
\hline Variable & Baseline cost estimate $(€)$ & Range tested $(€)$ \\
\hline Costs of transplantation (recipient) & 118,457 & $82,920-153,994$ \\
\hline Costs of lobectomy (donor) & 17,424 & $12,197-22,651$ \\
\hline Costs for donor evaluation & 1976 & $1383-2569$ \\
\hline Annual costs of decompensated cirrhosis & 12,848 & $8,994-16,702$ \\
\hline Costs of first year after transplantation & 17,955 & $12,568-23,341$ \\
\hline Costs for following years after transplantation & 10,218 & $7,153-13,283$ \\
\hline
\end{tabular}


TABLE 3. Lifetime costs, life expectancy, QALY, and cost-effectiveness

\begin{tabular}{lcccc}
\hline \multicolumn{1}{c}{ Strategies } & $\begin{array}{c}\text { Life expectancy } \\
\text { (years) }\end{array}$ & $\begin{array}{c}\text { QALY } \\
\text { (years) }\end{array}$ & $\begin{array}{c}\text { Lifetime costs } \\
(€)\end{array}$ & $\begin{array}{c}\text { Marginal cost- } \\
\text { effectiveness }(€ / \text { QLY) }\end{array}$ \\
\hline Natural history & 4.01 & 2.4 & 51,506 & \\
C-OLT & 11.20 & 8.6 & 191,139 & 22,451 \\
C-OLT + L-OLT & 12.74 & 9.9 & 222,215 & 23,530 \\
\hline
\end{tabular}

C-OLT, cadaveric OLT; L-OLT, living-donor OLT.

TABLE 4. Changes in mortality by treatment strategy

\begin{tabular}{lcccc}
\hline \multicolumn{1}{c}{ Strategies } & $\begin{array}{c}\text { Mortality of } \\
\text { original liver } \\
\text { disease } \\
(\%)\end{array}$ & $\begin{array}{c}\text { Perioperative } \\
\text { mortality } \\
(\%)\end{array}$ & $\begin{array}{c}\text { Excess mortality } \\
\text { after OLT } \\
(\%)\end{array}$ & $\begin{array}{c}\text { Natural age- and } \\
\text { sex-specific } \\
\text { mortality } \\
(\%)\end{array}$ \\
Natural history & 97.7 & & & 2.3 \\
C-OLT & 38.1 & 1.2 & 15.9 & 44.9 \\
C-OLT + L-OLT & 27.1 & 1.4 & 19.0 & 52.4 \\
\hline
\end{tabular}

C-OLT, cadaveric OLT; L-OLT, living-donor OLT.

will rise considerably with the number of transplantations performed.

\section{Variation of Living-Donor OLT Probability (Compared With Cadaveric OLT Alone)}

Again, when varying the probability of living-donor OLT (in a program with cadaveric OLT and living-donor OLT combined), marginal costs and marginal effectiveness of living-donor OLT (compared with cadaveric OLT alone) will change simultaneously, and therefore the cost-effectiveness ratio will stay stable below $€ 35,000 /$ QALY (Fig. 5).

We varied discount rates $(0-7 \%)$, short- and long-term costs $( \pm 30 \%)$, effectiveness data $( \pm 30 \%)$, and utility values $( \pm 30 \%)$. The results were not sensitive to these changes.

\section{DISCUSSSION}

Cadaveric OLT has advanced as the standard therapy for patients with ESLD. With a growing number of transplantations the problem of a progressive shortage of donor organs with an increasing size of the waiting list arises. A longer waiting time for transplantation leads to higher morbidity and mortality for patients with ESLD. Living-donor OLT is one approach to overcome the donor shortage. Survival and impact on quality of life after cadaveric OLT and living-donor OLT have been evaluated in several clinical studies and are well documented $(5,38-40)$. Nevertheless there is little data on the cost-effectiveness of cadaveric $\operatorname{OLT}(7,41)$ and there is no published data on the cost-effectiveness of living-donor OLT. Thus our study analyzed the effectiveness (life-years and QALYs gained), lifetime costs, and the cost-effectiveness of three strategies (natural history, cadaveric OLT alone, and cadaveric OLT or living-donor OLT combined) for the treatment of ESLD based on original data from the University Hospital Zürich and literature.

Cadaveric OLT gains an average of 6.2 QALYs compared with conservative treatment. Cadaveric OLT or living-donor OLT combined gives a patient an additional 1.3 QALYs compared with cadaveric OLT alone. Although costs of liver transplantation remain high with mean patient lifetime costs of $€ 191,139$ for cadaveric OLT and $€ 222,215$ for a combined cadaveric OLT and living-donor OLT program, the cost-effectiveness is favorable because of high effectiveness in treating
FIGURE 2. Five-year survival (\%) and marginal cost-effectiveness of cadaveric OLT (C-OLT) alone and cadaveric and living-donor OLT (C-OLT + L-OLT) combined (in €/QALY).

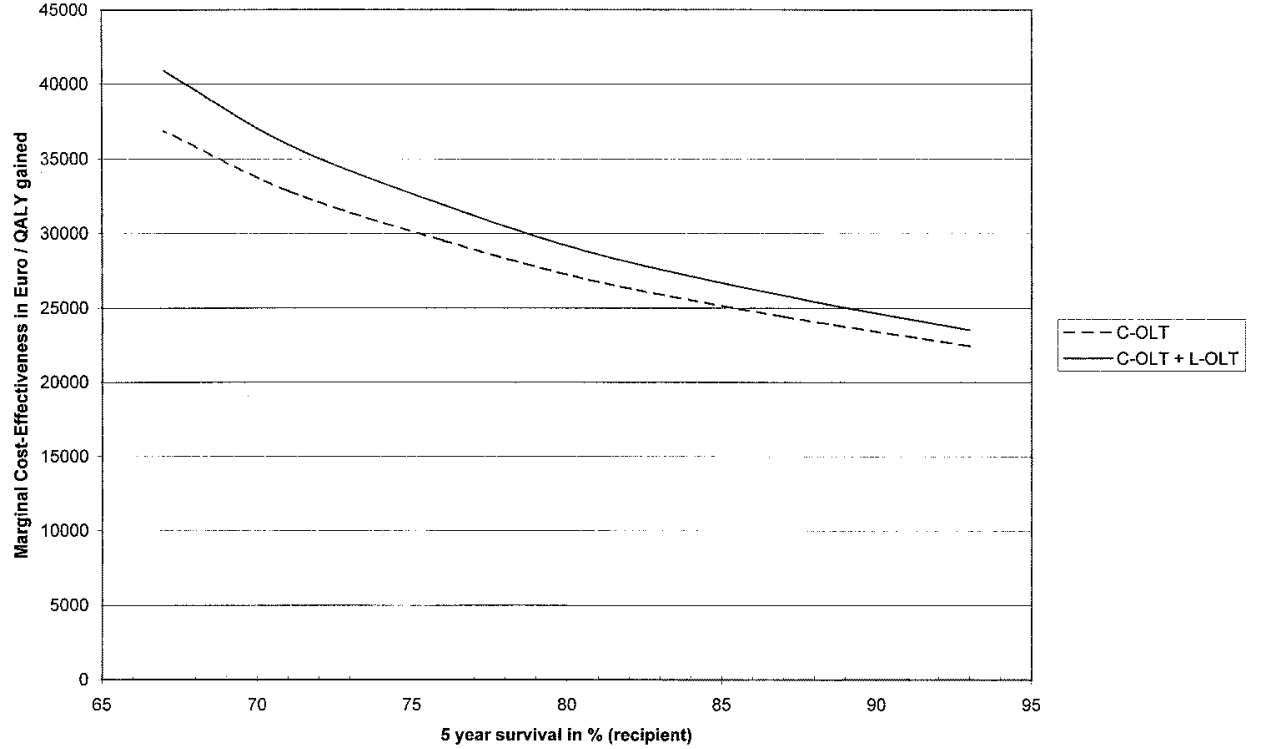




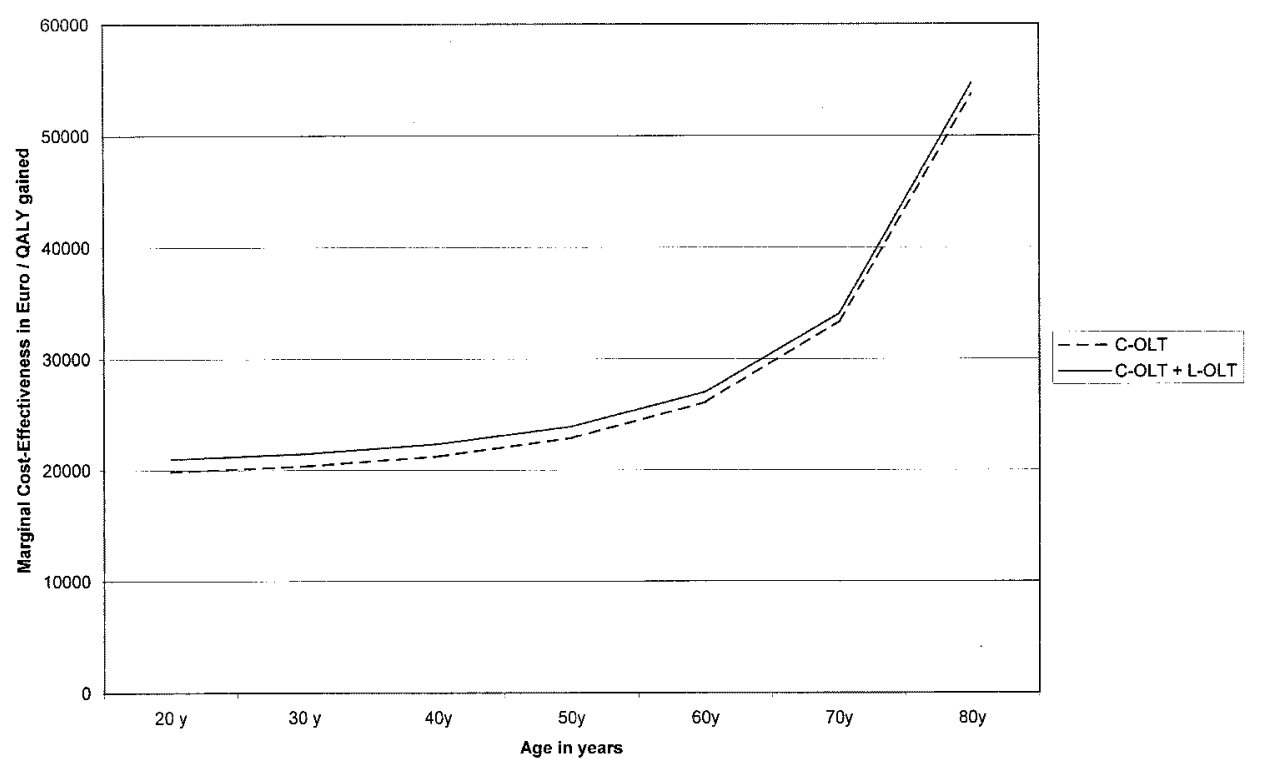

Figure 3. Age (years) and marginal cost-effectiveness of cadaveric OLT (C-OLT) alone and cadaveric and living-donor OLT (C-OLT + L-OLT) combined (in $€ / Q A L Y)$.

patients with ESLD, compared with conservative treatment without a transplantation. Both cadaveric OLT ( $€ 22,451 /$ QALY gained) and combined OLT and living-donor OLT ( $€$ 23,530/QALY gained) are cost-effective.

We performed our calculations with a favorable 5-year survival rate after transplantation of $93 \%$ as observed at the University Hospital Zürich. Other ELTR data suggest a 5-year survival of $83 \%$. Patients treated at the University Hospital Zürich may not represent patients or care patterns at other European centers. Nevertheless even with considerable lower survival rates (5-year survival rate reduced to $69 \%$ ), the cost-effectiveness ratio remained below $€ 35,000 /$ QALY. Costs per health state are derived from Swiss cost structures and Swiss treatment patterns. National costs are difficult to transfer to other countries with different healthcare systems, and differences are highly dependent of changing exchange rates, especially between Europe and the United States. Transplantation costs in Europe are lower compared with the United States (exchange rates March 2001): transplantation costs, Switzerland, € 118,457, United Kingdom, € 49,920-70,200 (8), United States, € 156,000 (9) to $€ 217,674$ (10); transplantation costs and first-year costs of follow-up, Switzerland, € 132,530, the Netherlands, € 87,369 (41), France, € 85,800 (42). Costs in Switzerland are at the upper limit of published costs in European countries, close to the costs in the United States. In a sensitivity analysis we increased costs of transplantation up to $€ 217,674$ (upper limit of published transplantation costs in the United States (10)), and the marginal cost-effectiveness stayed below $€$ 35,000/QALY gained. Collectively, despite the national differences in costs, our results on cost-effectiveness were stable and therefore transferable to other European countries as well as to the United States. Costs of long-term complications for the living donor were not included in our analysis as these have not been evaluated systematically (24). Nevertheless, based on the experience of liver lobectomies in the past, we do

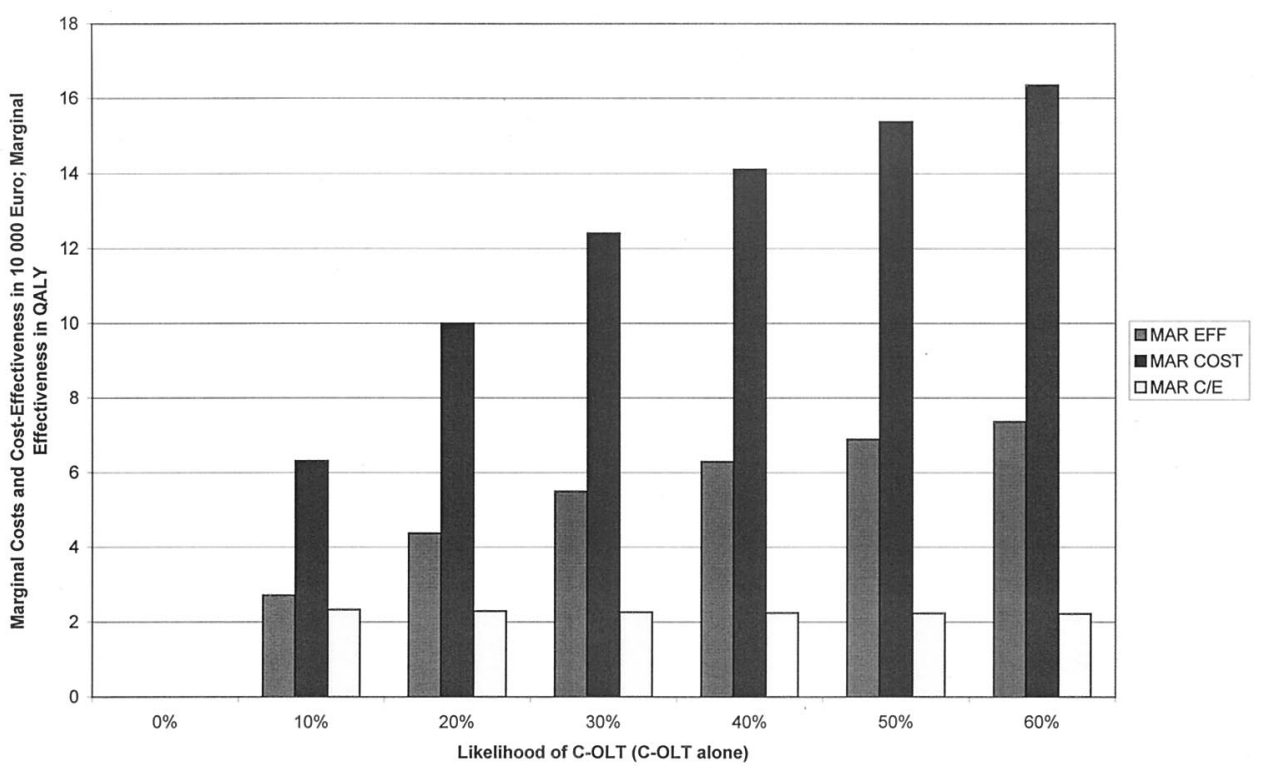

Figure 4. Probability of cadaveric OLT (C-OLT; in \%) and marginal effectiveness (MAR EFF; QALY), marginal costs (MAR COST; $€$ ), and marginal cost-effectiveness (MAR C/E; $€ / Q A L Y)$ in a program with C-OLT alone compared with conservative treatment (per patient). 
FIGURE 5. Probability of livingdonor OLT (\%) and marginal effectiveness (MAR EFF; QALY), marginal costs (MAR COST; $€$ ), and marginal cost-effectiveness (MAR $\mathrm{C} / \mathbf{E}$; $€ / Q A L Y)$ in a program with cadaveric OLT and living-donor OLT (C-OLT + L-OLT) combined compared with cadaveric OLT alone (per patient).

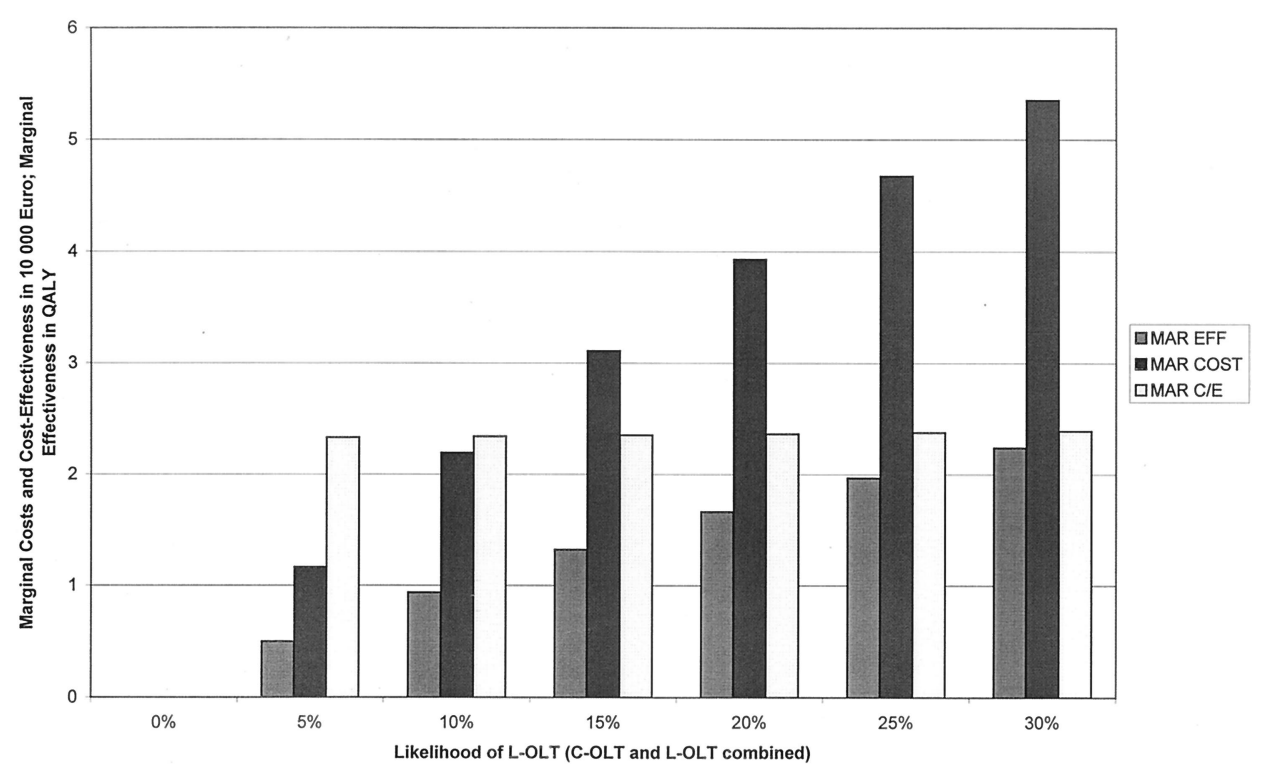

not expect serious long-term complications. The exclusion of these costs biases our result in favor of living-donor OLT. To be conservative we kept the annual likelihood of cadaveric OLT constant over time even when evaluating a combined cadaveric OLT and living-donor OLT program. The upcoming use of living-donor OLT might decrease the waiting list and increase the annual probability of cadaveric OLT. A calculation of a constant likelihood of cadaveric OLT biases our results against living-donor OLT.

Only a minority of approximately $15 \%$ of patients will find a suitable living donor within the first year after listing. This compares with an annual $39 \%$ chance of a cadaveric OLT until a patient dies of ESLD or natural mortality. It seems that the problem of a rising waiting list with a high mortality for ESLD will therefore not be solved by the introduction of a living-donor OLT program alone. Other alternatives to further decreasing waiting time have to be evaluated (3).

Living-donor OLT caries risks for the donor as well as for the recipient, and the implementation of a living-donor OLT program incorporates high surgical demands and a high ethical responsibility as well. To guarantee an optimal level of safety for the donor and the recipient, we suggest a critical quality assessment of centers that plan to start a livingdonor OLT program. These centers have to prove experience and excellency in the technical demands of cadaveric OLT and complex liver resections as well as biliary reconstruction (43). To facilitate a quality assessment of ongoing programs, centers should report their outcome to national and international surgical boards. Patients who are considered for a living-donor OLT program must meet the criteria for a cadaveric OLT program as suggested by Cronin et al. (44) to prevent disadvantage to patients on the waiting list for cadaveric OLT.

We conclude that cadaveric OLT and living-donor OLT are cost-effective relative to other therapies in medicine, e.g., $€$ $31,600 /$ QALY gained for coronary stenting with single-vessel disease (45) or $€$ 3,380-17,100/life-year gained for cholesterol-lowering therapy with a statin (46). Although OLT accrues high costs for a transplantation center, its remarkable effectiveness in giving patients with ESLD a 5-year survival of
$>80 \%$ leads to a well-accepted cost-effectiveness ratio. Living-donor OLT alone plays an important role in decreasing mortality for ESLD, but as long as only approximately $15 \%$ of patients find a suitable donor, alternative solutions have to be sought.

\section{REFERENCES}

1. Swisstransplant. Livertransplantation. Geneva 2000.

2. Neuberger J. Liver transplantation. J Hepatol 2000; 32(1 suppl): 198.

3. Trotter JF. Expanding the donor pool for liver transplantation. Curr Gastroenterol Rep 2000; 2: 46.

4. Trotter JF. Selection of donors and recipients for living donor liver transplantation. Liver Transpl 2000; 6(6 suppl 2): S52.

5. Marcos A, Ham JM, Fisher RA, Olzinski AT, Posner MP. Single-center analysis of the first 40 adult-to-adult living donor liver transplants using the right lobe. Liver Transpl 2000; 6: 296 .

6. Grewal HP, Thistlewaite JR Jr, Loss GE, et al. Complications in 100 living-liver donors. Ann Surg 1998; 228: 214.

7. Kankaanpaa J. Cost-effectiveness of liver transplantation. Transplant Proc 1987; 19: 3864.

8. O'Grady JG. Clinical economics review: liver transplantation. Aliment Pharmacol Ther 1997; 11: 445.

9. Evans RW, Manninen DL, Dong FB. An economic analysis of liver transplantation. Costs, insurance coverage, and reimbursement. Gastroenterol Clin North Am 1993; 22: 451.

10. Showstack J, Katz PP, Lake JR, et al. Resource utilization in liver transplantation: effects of patient characteristics and clinical practice. NIDDK Liver Transplantation Database Group [see comments]. JAMA 1999; 281: 1381.

11. Sonnenberg FA, Pauker SG. Decision Maker. New England Medical Center. Boston, 1999.

12. Fattovich G, Giustina G, Schalm SW, et al. Occurrence of hepatocellular carcinoma and decompensation in western European patients with cirrhosis type B. The EUROHEP Study Group on Hepatitis B Virus and Cirrhosis. Hepatology 1995; 21: 77.

13. D’Amico G, Morabito A, Pagliaro L, Marubini E. Survival and prognostic indicators in compensated and decompensated cirrhosis. Dig Dis Sci 1986; 31: 468 .

14. Fattovich G, Giustina G, Degos F, et al. Morbidity and mortality in compensated cirrhosis type C: a retrospective follow-up study of 384 patients [see comments]. Gastroenterology 1997; 112: 463.

15. Gines P, Quintero E, Arroyo V, et al. Compensated cirrhosis: natural history and prognostic factors. Hepatology 1987; 7: 122.

16. European Transplantation Registry. Survival of patients with cirrhosis as first indication of liver transplantation. Villejuif: ELTR, 2000.

17. Bundesamt für Statistik. Sterbetafel./1997. Neuchatel, 1996.

18. Beck JR, Pauker SG, Gottlieb JE, Klein K, Kassirer JP. A convenient 
approximation of life expectancy (the "DEALE"). II. Use in medical decision-making. Am J Med 1982; 73: 889.

19. Trotter JF, Wachs M, Trouillot T, et al. Evaluation of 100 patients for living donor liver transplantation. Liver Transpl 2000; 6: 290.

20. Broelsch CE, Malago M, Testa G, Gamazo CV. Living donor liver transplantation in adults: outcome in Europe. Liver Transpl 2000; 6(6 suppl 2): $\mathbf{S} 64$.

21. Todo S, Furukawa H, Jin MB, Shimamura T. Living donor liver transplantation in adults: outcome in japan. Liver Transpl 2000; 6(6 suppl 2): S66.

22. Bundesamt für Statistik. Statistisches Jahrbuch der Schweiz. Zürich, 1999.

23. Marcos A. Right-lobe living donor liver transplantation. Liver Transpl 2000; 6(6 suppl 2): S59.

24. Renz JF, Roberts JP. Long-term complications of living donor liver transplantation. Liver Transpl 2000; 6(6 suppl 2): S73.

25. VESKA. VESKA Diagnosenstatistik. Aarau, 1997.

26. Schweizerisches Institut für Krankenhauswesen. Lebertransplantation in der Schweiz. Aarau, 1989.

27. Vereinigung der Schweizer Aerzte. Tarmed. Bern, 2000.

28. Gold MR SJ, Russel LB, Weinstein MC. Cost Effectiveness in health and medicine. New York: Oxford University Press, 1996.

29. Read JL, Quinn RJ, Berwick DM, Fineberg HV, Weinstein MC. Preferences for health outcomes. Comparison of assessment methods. Med Decis Making 1984; 4: 315.

30. Sagmeister M WJB, Mullhaupt B, Renner LR. A pragmatic and costeffective strategy of a combination therapy with alfa $2 \mathrm{~b}$ interferon and ribavirin for the treatment of chronic hepatitis C. Eur J Gastroenterol Hepatol, 2001; 13(5): 483.

31. Bonsel GJ, Essink-Bot ML, Klompmaker IJ, Slooff MJ. Assessment of the quality of life before and following liver transplantation. First results. Transplantation 1992; 53: 796.

32. Payne JL, McCarty KR, Drougas JG, et al. Outcomes analysis for 50 liver transplant recipients: the Vanderbilt experience. Am Surg 1996; 62: 320.

33. Geevarghese SK, Bradley AE, Wright JK, et al. Outcomes analysis in 100 liver transplantation patients. Am J Surg 1998; 175: 348.

34. Pinson CW, Feurer ID, Payne JL, Wise PE, Shockley S, Speroff T. Healthrelated quality of life after different types of solid organ transplantation. Ann Surg 2000; 232: 597.
35. Salerno F, Borroni G, Moser P, et al. Survival and prognostic factors of cirrhotic patients with ascites: a study of 134 outpatients. Am J Gastroenterol 1993; 88: 514.

36. Mark DB, Hlatky MA, Califf RM, et al. Cost effectiveness of thrombolytic therapy with tissue plasminogen activator as compared with streptokinase for acute myocardial infarction. N Engl J Med 1995; 332: 1418.

37. Bundesamt für Statistik. Statistisches Jahrbuch der Schweiz. 2000.

38. Adam R, Cailliez V, Majno P, et al. Normalised intrinsic mortality risk in liver transplantation: European Liver Transplant Registry study. Lancet 2000; 356: 621 .

39. Kilpe VE, Krakauer H, Wren RE. An analysis of liver transplant experience from 37 transplant centers as reported to Medicare. Transplantation 1993; 56: 554 .

40. Marcos A, Fisher RA, Ham JM, et al. Selection and outcome of living donors for adult to adult right lobe transplantation. Transplantation 2000; 69: 2410 .

41. Bonsel GJ, Klompmaker IJ, Essink-Bot ML, Habbema JD, Slooff MJ. Cost-effectiveness analysis of the Dutch liver transplantation programme. Transplant Proc 1990; 22: 1481.

42. Rufat P, Fourquet F, Conti F, Le Gales C, Houssin D, Coste J. Costs and outcomes of liver transplantation in adults: a prospective, 1-year, follow-up study. GRETHECO study group. Transplantation 1999; 68: 76.

43. Broelsch CE. Results with living donor liver transplantation in Germany. Presented at the Workshop on Living Donor Liver Transplantation. Bethesda, MD, Dec 2000; 4-5.

44. Cronin DC 2nd, Millis JM, Siegler M. Transplantation of liver grafts from living donors into adults—-too much, too soon. N Engl J Med 2001; 344: 1633.

45. Cohen DJ, Breall JA, Ho KK, et al. Evaluating the potential cost-effectiveness of stenting as a treatment for symptomatic single-vessel coronary disease. Use of a decision-analytic model. Circulation 1994; 89: 1859.

46. Johannesson M, Jonsson B, Kjekshus J, Olsson AG, Pedersen TR, Wedel H. Cost effectiveness of simvastatin treatment to lower cholesterol levels in patients with coronary heart disease. Scandinavian Simvastatin Survival Study Group. N Engl J Med 1997; 336: 332.

Received 28 March 2001.

Revision requested 10 July 2001.

Accepted 29 August 2001. 